\title{
Heat Transfer Enhancement Techniques for Solar Air Collector Hater: Review
}

\author{
Fatah. O. Al Ghuol ${ }^{1}$, K.Sopian ${ }^{1}$, Shahrir Abdullah ${ }^{1}$, Mohammed Al-Ghoul ${ }^{1}$ \& Ali Whaad ${ }^{2}$ \\ ${ }^{1}$ Solar Ener.Res.Inst., Faculty of Eng., Universiti Kebangsaan Malaysia, Selangor, Malaysia \\ ${ }^{2}$ Department of Mechanical Engineering, Universiti Putra Malaysia, Selangor, Malaysia \\ Correspondence: Fatah. O. Al Ghuol, Solar Ener.Res.Inst., Faculty of Eng., Universiti Kebangsaan Malaysia, \\ Selangor 43600, Malaysia. Tel: 60-1-4292-3144. Email: waal85@yahoo.com
}

Received: January 31, 2015

Accepted: February 20, 2015

Online Published: June 22, 2015

doi:10.5539/mas.v9n9p20

URL: http://dx.doi.org/10.5539/mas.v9n9p20

\begin{abstract}
Nowadays, industrial are widely use solar air collectors for low moderate temperature applications such as like timber seasoning, crop drying, and space heating. The high performance of the energy conversion and energy storage performance of the solar collectors has drawn the increasing attention energy research field. This paper focuses on reviewing the developments different types of solar thermal and its applications, providing a review of solar collectors and methods of performance enhancement. The goal of this review is to provide the necessary information for future solar power stations are overview.
\end{abstract}

Keywords: heat transfer, solar, air collector

\section{Introduction}

Solar air heaters are simple devices that utilize incident solar radiation to obtain clean energy for a wide usage. The solar air heater device intercepts solar radiation, converts this radiation to the heat in air and delivers the air for use. The main components of a solar air heater is an absorber plate, one or more channels for the flowing air, insulation for the bottom and lateral sides of the solar collector and one or more transparent covers. The use of a blower is optional for the air supply.

\section{Solar collectors}

The high energy storage performance and efficiency have led to plan thermal applications which increased attention of the research to enhance solar energy. A solar collector has ability to convert the solar energy to the working fluid thermal energy for applications of solar energy and also directly to an electrical energy for the applications of Photovoltaic. The applications of solar heating were absorbed as heat by solar collector which was transported to the operation liquid. The heat transferred by the liquids may be utilized for heating to provide local hot water or to benefit the heating storage trough which might be used the heat later (for cloudy days or night). For applications of PV, it was not only converted the solar radiation to electrical energy, but the different waste heat production, which was recollect for heating utilized by board PV attaching with recovering the working liquids filled tube (De Winter, 1991).

\subsection{Flat plate Collector}

The solar collector with flat plate were always faced to direction, and also, need to be on proper faced. A flat plate solar collector permanently included to covers with glass, plates for absorber, layers for insulation, recuperating tubes and other auxiliaries. The cover with glass reduced convective losses from the plate absorber, and also reduced the collector radiation losses cause to the influence of greenhouse. The reason to consider a desirable material glazing as low iron glass was high transmittance relatively for solar heating approximately from 0.85 to 0.87 and the necessary low transmittance for the long wave solar radiation from $5.0 \mathrm{~lm}$ to $50 \mathrm{~lm}$ (Khoukhi and Maruyama, 2005; Parsons, 1995; Hellstrom et.al., 2003). Hellstrom et al. (2003) was performed the effect of thermal properties and optical on the solar collectors with flat plate performance and concluded that the efficiency enhance by $5.6 \%$ at $50^{\circ} \mathrm{C}$ when adding of a Teflon film as second glass layer, whereas a Teflon honeycomb installation for decrease the loss of convective was provide the overall efficiency by $12.1 \%$. Furthermore, the glazing cover antireflection treatment was provided the output by $6.52 \%$ at $55^{\circ} \mathrm{C}$ working temperature. Coating plate absorbers with blackened surface for absorption too much possible heat; however 
various color coatings was reported in the literatures (Tripanagnostopolous et.al., 2000; Wazwaz et.al., 2002; Orel et.al., 2002). Selective surfaces desirable was consisted of an upper thin layer which was absorbed maximum solar intensity with shortwave and approximately transferred to thermal radiation with long wave, and the lower layer that was the low emittance and the high reflectance for high wave radiation. Some desirable optical surfaces efficiency selective normally production a high cost, but several low cost production ideas were also reported (Konttinen et.al., 2003). Likewise, the solar plate for enhancing thermal efficiency, the absorber losing heat also needs to decrease. Francia (1961) was studied that the insertion of honeycomb, which was consisted of transparent material with faced to the gap air between the absorber and glazing which also, reduced the heat loss. The absorbing heat by the plate absorber should be rapidly transported to liquids for preventing the system of the overheating (Slaman and Griessen, 2009). Kumar and Reddy (2009) were introduced the solar receivers heat transfer with porous medium and concluded heat transfer enhancement significantly by $64.3 \%$. Lambert et al, (2006) were studied that the flow oscillation may significantly increase the heat transfer when thermal diffusivities improving of the solar collector's fluids. Ho et al. (2005) were presented a structure of double pass to receive solar and benefit a best heat transfer rate.

\subsection{Hybrid Photovoltaic Thermal (PVT) Collector}

Hybrid PVT collector have converted solar radiation into heat and electricity directly (Aste et.al., 2008). A typical PVT collector included to PV module of an optimum performance with range of $5 \%$ to $20 \%$ and plate absorber with PV back module. The plate heat removal cooled the PV module to a proper temperature for high electrical efficiency at same time is collecting the waste heat, that may use for low temperature applications, as adsorption cooling systems and production hot water (washing and showering) (Wang and Zhai,2012). Recently, most of the significant researches on PVT collectors were related to collectors of flat plate. Many investigations were focused to tube dimensions and absorber plate (Bergene and Lovvik,1995), rates of fluid flow (Kalogirou, 2001; Prakash,1994), size of tank (Agarwal and Garg, 1994), packing factor of PV cell (Fujisawa and Tani; 2001), amorphous silicon using (LESOPB et.al., 2000, Platz et.al., 1997], metal fins using (Tonui and Tripanagnostopoulos, 2007), and multiple passage configurations (Hegazy, 2000). The numerical method for these collectors has been studied the relation of electrical energy and thermal output (Coventry, 2002; Zondag et.al., 2002). Furthermore, the PVT collector's exergy analysis, based on the Thermodynamics (second Law) (Joshi and Tiwari, 2007).

\subsection{Bifacial PVT Collectors}

The hybrids collector may divide to those utilize liquid for removing the heat, and also using the air. $\mathrm{H}_{2} \mathrm{O}$ was the operating liquid in the collectors of hybrid PVT, due to its high capacity heating and good properties. Tina et.al., (2012) were examined submerge water solar heating system and concluded the $4 \mathrm{~cm}$ layer thickness which decreased the thermal drift and the reflection of their system and reduced the PVT performance by $14 \%$. Firstly, the sunlight mainly was absorbed water of the infrared area and secondly, the fully transparent of water in the short wavelength area have been related reasons for efficiency boost. The long wavelength intensity may be absorbed by liquid for heat production and short wavelength radiation may be used by PV design for electricity production. Water natural compatibility of PV design has been confirmed by (Palmer and Williams, 1974); Robles-Ocampo et.al., 2007; Nelson, 2003). The lower curves like the short circuit current Isc of the rear face alone at various day times; the middle curves of Isc for front panel; the upper curves represents the total Isc at different the PV module face. They were illustrated that PV module production by $38 \%$ more electrical energy than the available PVT system, without increasing of the system cost noticeable.

\subsection{Heliostat field Collectors (HFC)}

The HFC which noun as central receiver included of many flat mirrors heliostats. The arrays of heliostats/mirrors needs to have true direction for reflecting incident lights of solar to a general tower because the position changes of the sun at day. The orientation of each unique heliostat was controlled by the automatic control system which provided power by tracking altazimuth technique. Likewise, the optimized field layout design was needed in order to put those heliostats with a significant overall optical performance. Wei et al. (2010) were reported the technique noun 'YNES' in order to arrange the field layout optimization. The field layout optimization of heliostats may be reflected the light of solar to the main tower, where a location of a steam generator was absorbed the heating energy and liquid heating up to the steam of high pressure and high temperature. The fluid heat transport through the steam generator may be liquid/steam, sodium as molten salts or liquid, whereas the thermal storage region may liquid sodium, or molten nitrate salt (Medrano et.al., 2010). The central solar collector's tower may be classified into cavity and external type. The receiver was utilized the external type solar at Barstow, California, USA which indicated in Figure 1. 


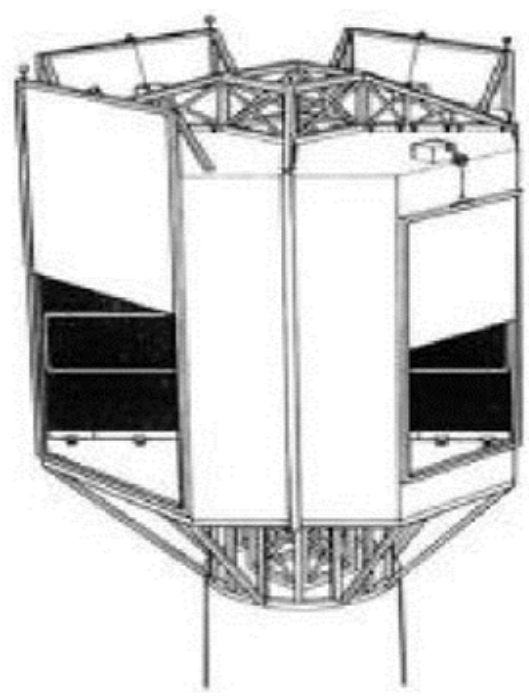

(a)

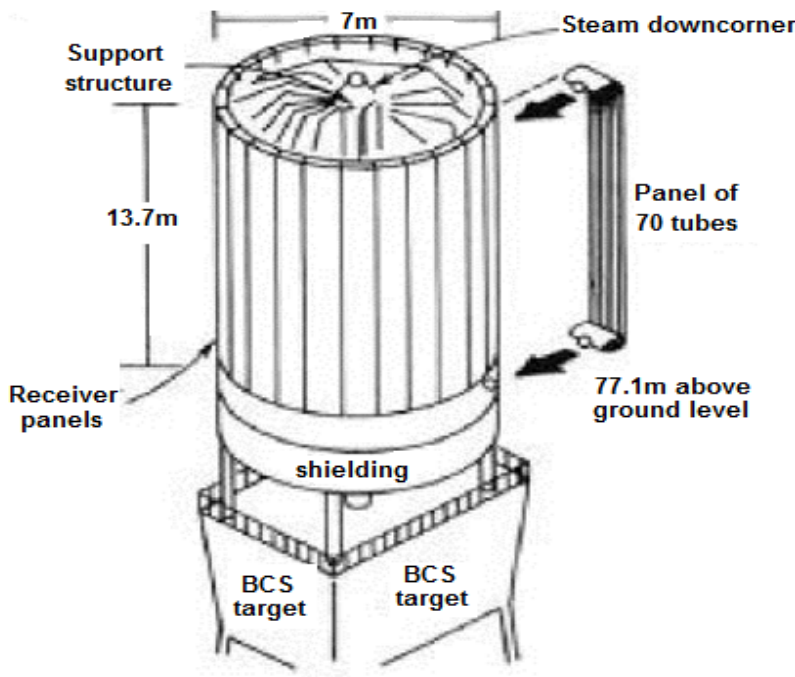

(b)

Figure 1. Solar tower types (Battleson, 1981): (a) cavity receiver and (b) external receiver

It has been positioned up to the central tower; the comparison of 25 layers ( $7 \mathrm{~m}$ receiver diameter) has been conducted and six of which preheated liquid and eighteen for vapor production. Typically the external receivers with a diameter ratio of 2:1 to were tested. The receiver area was normally arranged to be as minimum as possible to reduce heat loss. Although, receiver lower limit region was evaluated by the tubes optimum temperature operation, the heat exchanger and removal heat capability of the fluid transport, in order to prevent the overheated happened to fluid heat transfer. The lower limit of the receiver region may decrease by utilized the higher temperature tolerance tubes, or using the higher heat removal capability of fluid heat transport. The heat transfer fluid consists of liquid/steam, molten salts and liquid sodium, synthetic oils between the molten salt and water sodium have higher heat capability removal than preparing oils and vapor (Battleson,1981). The limitation firstly to receiver design was heat flux that may absorb into the surface of receiver and transported through the fluid heat transfer, preventing the overheating walls receiver and the fluid heat transfer within them. The entire wall average flux over absorber was typically 0.3 to 1.3 of the optimum values. Other two significant consumptions which arranging heat flux were the temperature gradients limiting along to panels receiver and the heat cycle daily of the receiver of tubes.

\subsection{Parabolic Dish Collectors}

Parabolic dish collectors (2012) were used the parabolic dish array which has mirrors shape like to the dish of satellite) for focusing solar radiation to the receiver which located at the general local position of a dish faces. Convection heat transfer which consisted of the receiver was then heated up to operation pressures and temperatures so as to create electrical power of an engine receiver attachment (Stirling engine, report 2014). The engines under taken were included Sterling (Tavakolpour et.al., 2008) and engines of Brayton (Zhang et.al., 2007). In USA number of systems with prototype dish engine, under the range of (7- 25) $\mathrm{kW}$ were deployed in different area. The advantages of dish engine systems (Parabolic type) as follow: low startup losses, high efficiency of an optical and good modularity which may easy scaled up for meeting the power needed for remote area which centralized as too expensive power supply. The technologies of parabolic dish engine were illustrated for many applications proposed for America (2012).

\subsection{Parabolic Container Collectors}

Parabolic container collectors may focus the sunlight with the rate of concentration around 50, with the container size. The temperature of the focal line may be as high as $300^{\circ} \mathrm{C}$ to $340^{\circ} \mathrm{C}$. The main components of these collectors are parabolic mirrors to reflect solar radiation in symmetry axis to its general line of focal. The line of focal which metal receiver was tube covering of glass for heat loss reduction was placed for absorbing the heat collection. The parabolic container collectors may be faced either in a south-north direction or an east-west direction, tracking the sun from east to west. An experimental work was conducted by (Bakos, 2006) study influence of parabolic axis trough tracking on the collected of sun light, and a comparison was made of the case which utilized a constant surface orientation. Significant results measured solar heating collector on the tracking 
face. Abdallah (2004) was examined experimentally the influence of utilizing different solar tracking systems types on the current-voltage parameters and electrical energy of flat-plate PV for four types comparison of electromechanical solar energy systems: north-south axis, east-west axis, and one, two vertical axis, ,. The results showed that the ampere-volt parameters on tracking faces has been greater than that on a constant face, with increasing of electricity energy get $15.69 \%, 34.43 \%, 37.53 \%$ and $43.87 \%$ respectively. Additionally, (Kacira et.al., 2004) were studied the peak tilt angle changed from $61^{\circ}$ in winter to $13^{\circ}$ in summer.

\section{Solar Air Heaters Types}

Solar air heaters divided based on main parts. First part was related to the flow configuration of air channel. Flow configurations of various air channels may be constructed to enhance the system efficiency. These configurations can be expressed in four sub titles under this subject. The sub title were; single flow single pass, double flow single pass, single flow double pass and single flow recycled double pass. The second part was related to the design air channel.

The air channel design affects the system efficiency significantly. For that reason various design configurations may be utilized in the solar collectors. The second category may also be expressed in three subtitles such as; flat plate, extended surface assisted, porous media assisted. All main and sub titles were explained below.

\subsection{Classification According to Air Channel Flow Configuration}

\subsubsection{Single Flow Single Pass}

Experimental study of porous media in solar air heater has been conducted by (Ben et.al., 1996). They concluded the effect of solar radiation and mass flow rate on solar collector efficiency. Single flow single pass was the most common and simplest type of solar air heater in Figure 2. Generally, a black plate has been utilized for a high rate of solar absorption and as a selective absorber plate. The air flow channel was insulated on the bottom and lateral sides for preventing heat loss. The insulation materials may be glass wool, polyurethane or rock wool. The solar radiations pass through the top cover (transparent part) to the absorber plate. The temperature of the absorber plate was increased since its bottom was insulated. The single flow single pass solar collector, there was an inlet and outlet for the air to enter and leaved the channel directly. That was why this kind of solar air heater was named as single flow single pass for many investigators (Foued et.al., 2013; Bhagoria et.al., 2002).

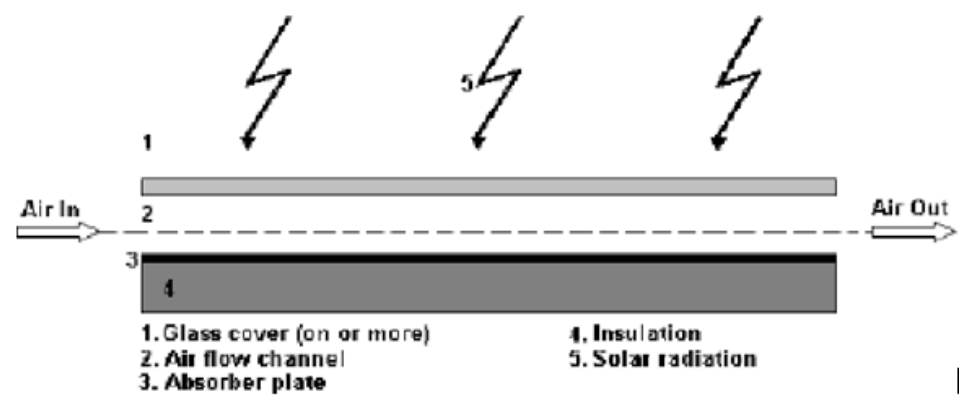

Figure 2. Single flow single pass

\subsubsection{Double Flow Single Pass}

Foued et al., (2013), the double flow solar performance studied and compare single pass and found that double pass operation increase solar collector efficiency. The double flow single pass solar was very similar to single flow single pass heater. The main difference between them was the number of air flow channels. In the double flow single pass solar air heater, there were two air channels as indicated in Figure 3. The top channel included of a solar absorber and a cover glass. The second channel located on the bottom of the first channel included of the same absorber plate (on top) with insulation (on bottom). The air was entered the collector as divided; half passes through the upper channel while the remainder flows through the bottom channel. For both channels, the airflow enters the channel and directly leaves it. That was why this kind of solar air hearer was defined a double flow single pass. Using a double flow single pass solar enhance the performance of the thermal system can be higher than a single flow model based on same flow rate (Ozgen et al., 2009). 


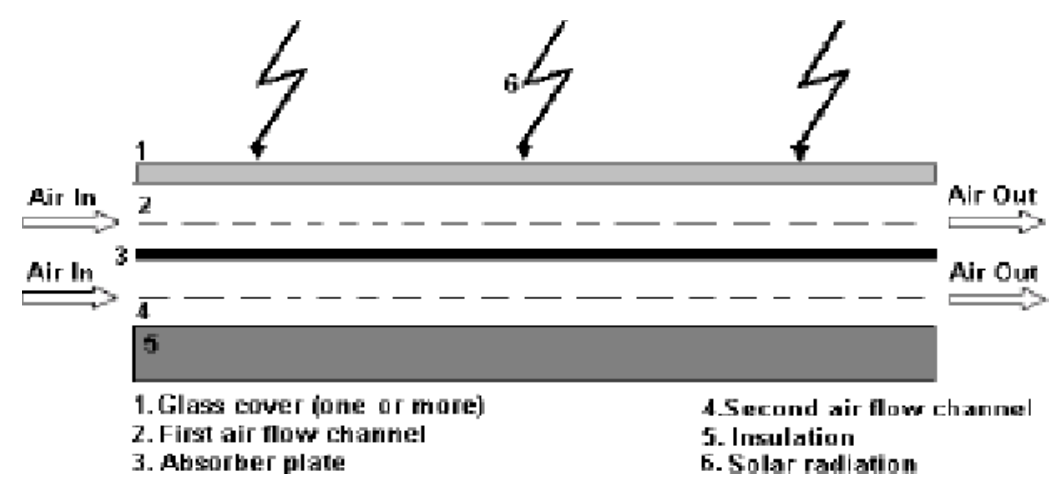

Figure 3. Double flow single pass

\subsubsection{Single Flow Double Pass}

The main goal of utilizing double pass arrangement is to reduce the heat loss to surrounding from the front collector face and also improving the thermal performance of the system (Peng et al., 2010). Gonzalez et al., (2012) studied the thermal efficiency of a double pass solar air heater which designed and manufactured at INENCO experimentally, and the thermal model developed to describe its thermal behavior theoretically. The results illustrated a temperature rise of $35^{\circ} \mathrm{C}$ with respect to the inlet air temperature, for a solar radiation around $900 \mathrm{~W} / \mathrm{m} 2$. The average daily efficiency of $34 \%$ has been concluded. Two overlapping air flow channels in a single flow double pass solar were selected. Air flows at upper channel, changes direction at the end of channel and enters the lower channel. It flows straight in the bottom channel. This is the main reason to define solar air heater as .single flow double pass. Figure 4a demonstrates one of them. It can be seen that there are two overlapping air flow channels.

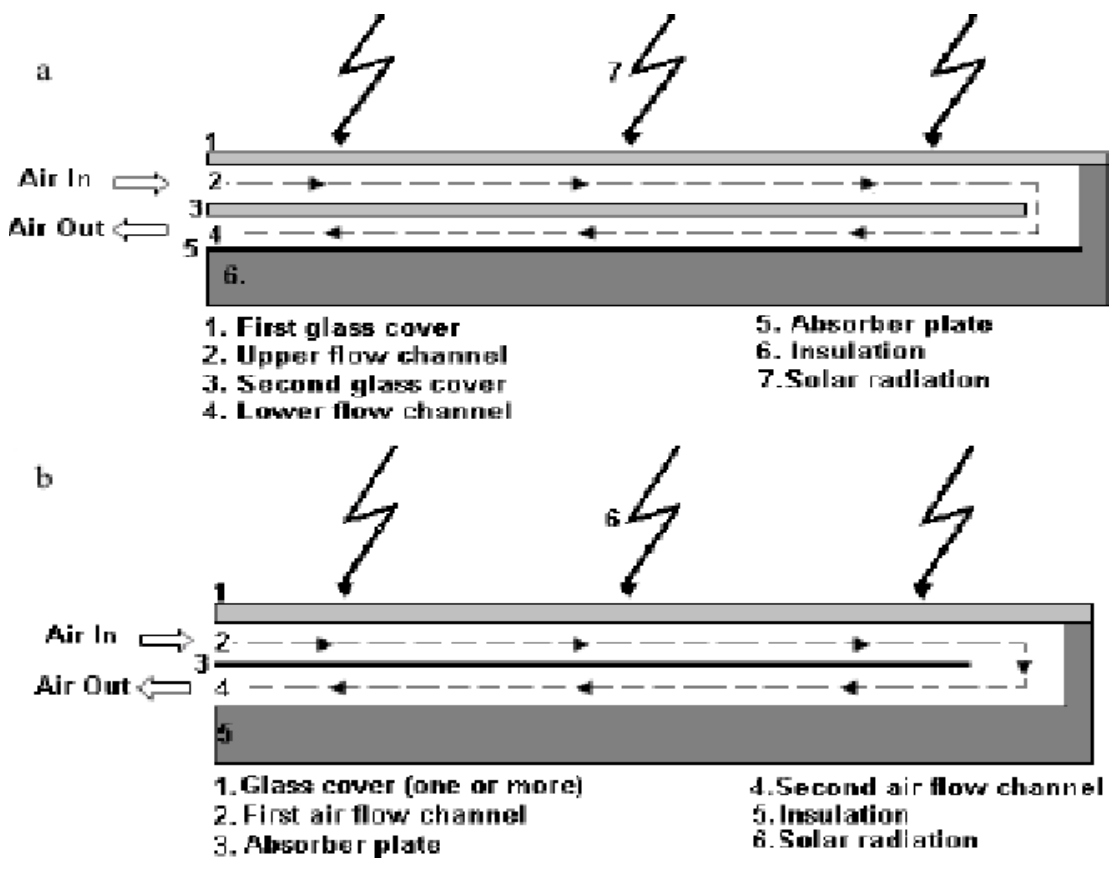

Figure 4. The single flow double pass with absorber plate, a) solar air heater with glass separator b) solar heating with absorber separator.

These channels are separated by a glass from each other and the absorber is placed at the bottom side of the lower channel. Air flows from the first and the second transparent sheet and is received by the absorber. The bottom side of the absorber is insulated. For the second design, the absorber plate is placed as a separator 
between the upper and lower channels as showed in Figure $4 \mathrm{~b}$. The upper air flow channel is formed by absorber plate and glass cover where the lower air flow channel has been located among the insulated lower plates and the same absorber plates (Ahmad et al. 2011).

\subsubsection{Single Flow Recycled Double Pass}

The using of recycled heated air in the solar air heater design can enhance its efficiency and adjust the air outlet temperature (Choudhury,1999). The partial circulation of the air heated may provide the desired air temperature at the exit of air flow if the temperature at outlet is different than the desired temperature. As shown in Figure 5, the solar air heater included of 2 channels. The upper channel is consisted by the absorber plate (underneath) and the glass cover (on top). The walls of the other channel are insulated. The heated air is transported to the bottom channel and then it flows into the main air flow channel. There is a single inlet and outlet in the system and this is the reason to call this type as single flow recycled double pass heater (Alvarez et al., 2004).

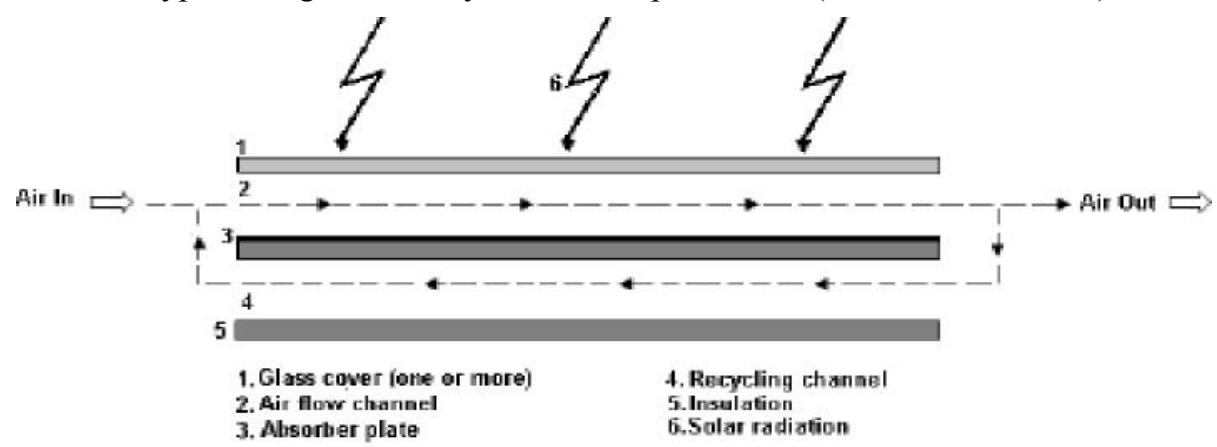

Figure 5. The single flow recycled double pass

\subsection{Classification According to Air Channel Design}

\subsubsection{Flat Plate}

The attention of researchers has given to analysis of flat plate solar heating by experimental work for cost and efficiency analysis of solar heating with two pass (Gaur, 2010). A flat plate collector utilized to heat the air commonly known as a solar heating (Gupta et al., 2013). The type of the flat plate is the simplest form of solar air heater. This solar heating type consists of an absorber plate and one or more glass covers as shown in Figure 6 . The solar heating sides except the glass cover must be well insulated for preventing the heat loss. Air may flow either under or over the absorber plate. Flat plate solar air heaters may be designed as single pass, double pass, double flow or recycled. The absorber plate has generally a smooth plate and it does not contain a fin, roughness element or obstacle. This reason to call this type of solar air heater is a Flat Air Channel. The Flat Air Channel solar air heater construction is simple; hence it has a low cost. Since no mechanism or method is utilized to improve the channel heat transfer, this kind of solar air heater efficiency is lower than other types (Gupta et al., 2013).

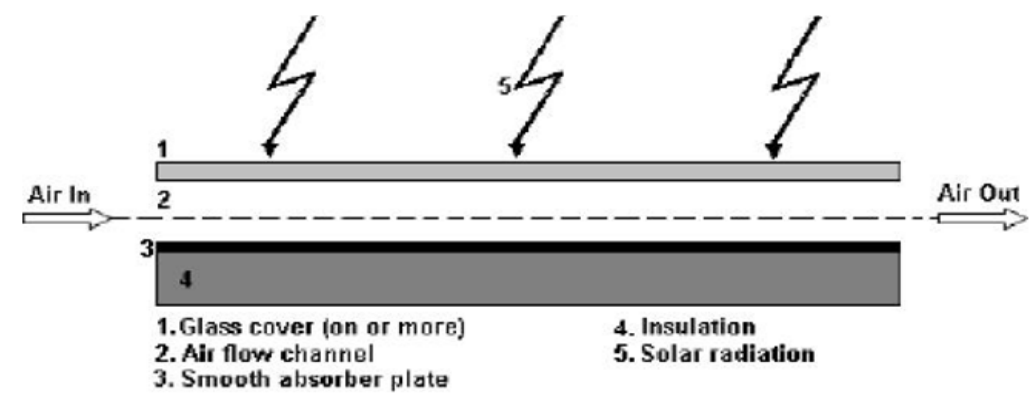

Figure 6. The flat plate solar air heater (Gupta et al., 2013)

\subsubsection{Extended Surface Assisted}

The thermal efficiency of the double pass solar air collector with finned absorber has been studied experimentally and analytically by (Bashira, 2005). The efficiency was increased to the mass flow rate and solar 
intensity, but the efficiency was depended to mass flow rate. Several designs were investigated for increasing the low thermal efficiency of flat air channel solar air heaters. Since the absorber plate type was one of the most important parameter that affected the thermal performance of the solar air heaters, number of absorber modifications were studied (Moummi et al., 2004). The surface area extension of the absorber plate may be an efficient way to enhance the solar air heaters efficiency. Attaching fins, obstacles, ribs or any other roughness element (any element that causes roughness to the absorber plate) on the absorber plate might extend the solar air heater surface area. The assistance of a solar air heater by an extended surface of air channel has a transparent cover, insulation material and a roughened absorber plate that absorbs the solar radiation. The fins mounted or roughness element to the absorber plate not only extended the absorption area but also increased the mixing of air flowing in the channel and consequently improved the heat transport coefficient. A solar heating collector with channel was assisted by an extended surface may be designed as a single pass, double flow, double pass or recycled model as indicated in Figure 7. Although the utilize of fins or roughness elements increase the heat transfer coefficient and surface area, the pressure drop through the channel can be increased with the same time. The channel pressure drop increasing may result, as the increase in the required power of the blower or fan that supplies the air to the heater was also required. That is why a lot of research has involved designing the roughness element or fin geometries (Omojaro et al., 2010).

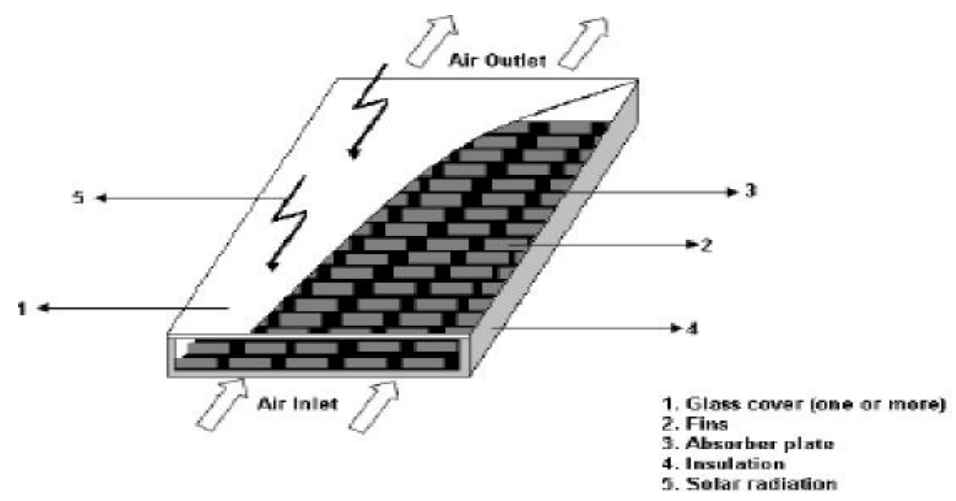

Figure 7. The fin assisted absorber plate (Omojaro et al., 2010)

\subsubsection{Porous Media Assisted}

Many researches were focusing on the air heater performance enhancement by integrating flat plate collector with energy storage systems and packed bed Ozturk, and Demirel (2004) [57]. The single pass solar heating and different porous media was conducted experimentally (Prasad et al., 2009). Their results indicated that the solar heating efficiency by using steel wool as a porous medium was higher than the glass wool as well as conventional air heater. The solar air heater channel with a porous medium assisted could be a useful way to improve the outlet air temperature and thermal efficiency. The packed bed utilization in solar air heater channel flowing was increased both the heat transport area and mixing of air stream. These solar heaters include an insulating material, a transparent cover, porous media and an absorber plate Figure 8 . The porous media was inserted in the channel flow of the solar air heater. The air flows into a channel in contact with the porous media which was in contact with the absorber. Assistance of porous media heaters may be designed as single pass, double pass or recycled but they were generally single flow double pass systems. The porous media may be chosen from high conductive materials to accelerate heat transfer between the porous media and the air flows inside the channel. The porosity of the porous media was very important parameter to indicate a pressure drop in the channel. Though the porosity decreasing improves the effective heat transfer coefficient, it also increases the pressure drop through the channel. This is the reason to perform these studies on the characteristics of porous media required for designing a system with high heat transfer rate and low pressure drop. There is no doubt that with the optimum porosity, thickness and position, the heat transfer between absorber and air flow through the channel may be improve considerably (Sopian et al., 2009). 


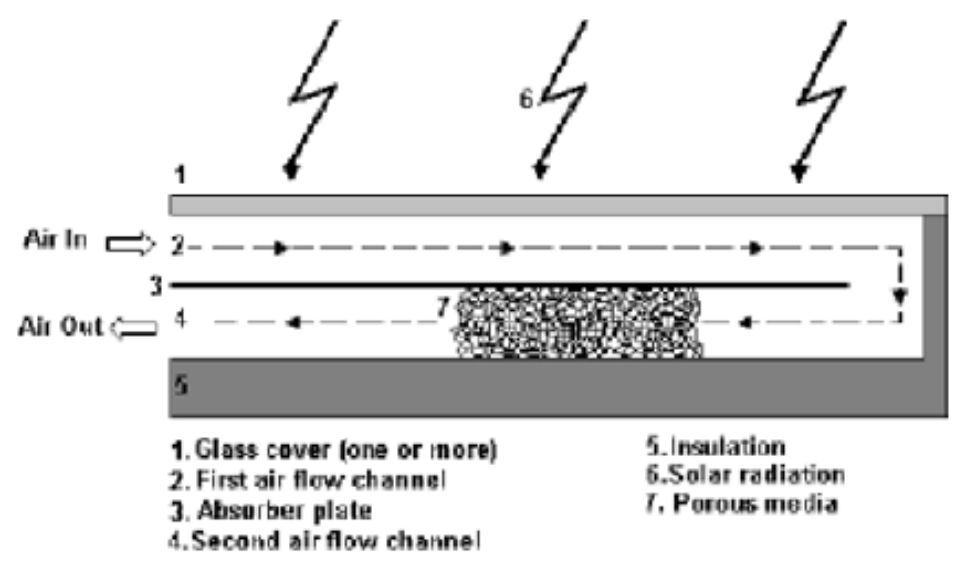

Figure 8. The porous assisted solar air heater (Sopian et al., 2009)

\section{Methods of Performance Enhancement}

\subsection{The High Conductive Materials for Heat Enhancement}

The PCM storage system for heat transfer may be improved by composing material with significant thermal conductivity (sensible heat phase) through the phase change materials (latent heat phase). For phase change materials/ceramic compound, the molten phase change materials was immobilized and retained for the small porosity which identified by the ceramic network surface tension and capillary forces, and offered the utilizing potential direct connect heat exchanger (Tamme et al., 1991). Petri et al, (1984) were examined a porous medium laboratory scale storage unit consisting $2.22 \mathrm{~kg}$ composite $\mathrm{BaCO} 3-\mathrm{Na}_{2} \mathrm{CO} 3$ (melting point of $800{ }^{\circ} \mathrm{C}$ ) $/ \mathrm{MgO}$. The composite material was compressed through cylindrical pellets with the height of $1.5 \mathrm{~cm}$ and the diameter of $2 \mathrm{~cm}$. The 200 cycling examined illustrated high stability of $\mathrm{BaCO}_{3}-\mathrm{Na}_{2} \mathrm{CO}_{2} / \mathrm{MgO}$ composite.

Gokon et al.,(2008) tested experimentally the using of feasibility of carbonate $\left(\mathrm{K}_{2} \mathrm{CO}_{3}-\mathrm{Na}_{2} \mathrm{CO}_{3}-\mathrm{Li} \mathrm{C}_{2} \mathrm{CO} 2\right)$ $\mathrm{MgO}$ composite material as a medium of heating storage for prolong the cooling time in a reactor with double wall. The graphite was also conducted as an enhancement heat transport cause to its good thermal conductivity, chemical resistance and low density (Zhang, et al., 2010). The paraffin graphite composite thermal conductivity may increase up to $70 \mathrm{Wm}^{-1} \mathrm{~K}^{-1}$ depending to the graphite percentage. The material cost can increase and also the size storage capacity can decrease by the fraction graphite increasing, the graphite content might limit. The plastic flexible capsules were utilized for low temperature phase change materials applications. To encapsulate the phase change materials and melt temperature above $210^{\circ} \mathrm{C}$, the material was commonly not cheap. If the capsule was utilized to include the phase change materials, the phase change materials initially volume might not exceed $75 \%$ to withstand the pressure drop through the cycle of solidification/melting. The parallel cylindrical capsule with the length of $0.5 \mathrm{~m}$ shows in Figure 9. They were filled with eutectic $\mathrm{NaNO}_{3}-\mathrm{KNO}_{3}$ and collected into the trough (Zhang et al., 2010).

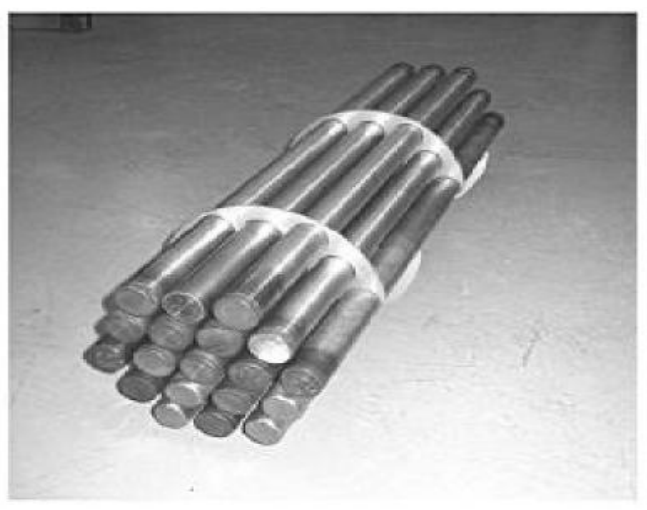

Figure 9. Laboratory scale test for cylindrical capsules utilization (Zhang et al., 2010) 


\subsection{Extended Heat Transfer Surface}

Heat transfer extension surface using finned tubes or capsules may decrease for heat transfer distance into phase change materials with heat transport enhancement. The material of fin may be aluminum, graphite foil, copper and steel. As shown in Table 1, the different materials relevant properties and costs (Bauer et al., 2006). The cost of volume specific was a quantity cost evaluated, density and thermal conductivity. The reason to provide the advantages with the graphite foil, like the low density, the good thermal conductivity and the high corrosion resistivity against nitrite and nitrate salts with temperatures higher than $210^{\circ} \mathrm{C}$, it was demonstrated as fin material experimentally as shown in Figure 10.

Table 1. fins materials properties considered (Bauer et al., 2006)

\begin{tabular}{|c|c|c|c|}
\hline Aluminum & $\begin{array}{l}\text { Carbon } \\
\text { steel }\end{array}$ & $\begin{array}{l}\text { nStainles } \\
\text { steel }\end{array}$ & s CopperGraphite \\
\hline Volume specific cost estimation 7000 & 15,000 & 20,000 & $40,000 \quad 10,000$ \\
\hline Density $\left(\mathbf{k g} / \mathbf{m}^{3}\right) \quad 2700$ & 7811 & 7800 & 8811999 \\
\hline Thermal conductivity (W/m.K)200 & 30 & 21 & 349 \\
\hline
\end{tabular}

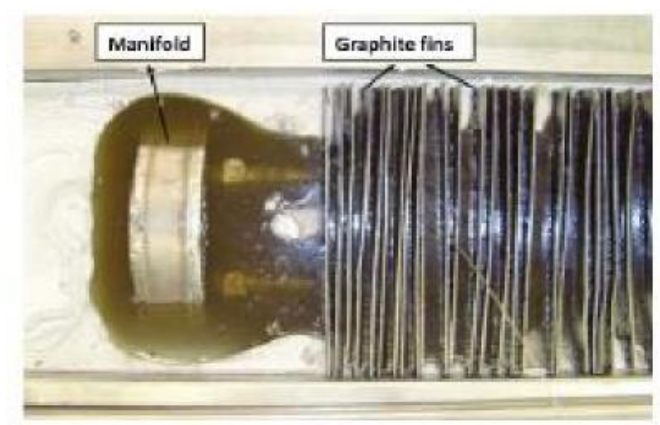

Figure 10. A storage graphite foil fins unit and PCM eutectic salts (Bauer et al., 2006)

\subsection{Intermediate Medium of Heat Transfer for Enhancement.}

The incorporating of heat storage concept with intermediate high fluid conductive was indicated in Figure 11 (Lopez et al., 2010), which defined as reflux heat transfer storage.

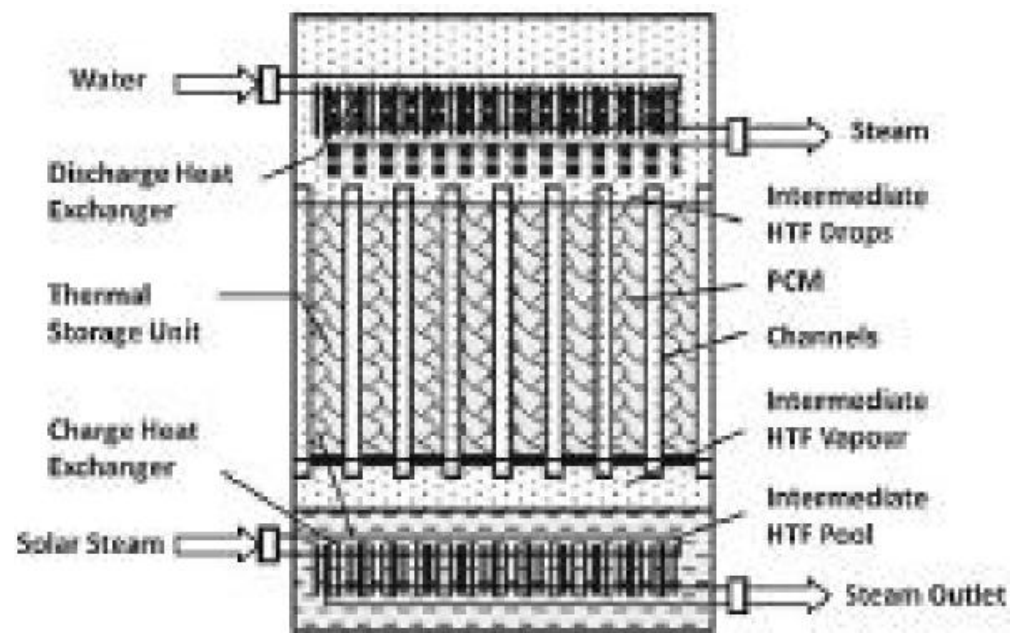

Figure 11. The reflux heat transfer storage concept (Lopez et al., 2010)

The concept has depended to the reflux condensation evaporation in the intermediate heat transfer fluid occurring. The whole system storage includes of a phase change materials, and heat exchangers. The liquid HTF 
was absorbed the energy into vaporization, in the charging process, and the vapor was flowing upwards into the transport channels phase change materials distributed. Then the vapor condenses on the surfaces of the channel and the latent heat of vapor was transferred to PCM across the walls. The liquefied heat transfer fluid was returned to pool cause for gravity. A PCM heat causes HTF liquid to evaporate, in the discharging process and the vapor energy transport to the operation liquid moving into the top heat exchanger. Firstly, the concept has been illustrated successfully by Adinberg et al, (2008). The chloride of sodium as phase change materials and sodium metal to temperature storage $700^{\circ} \mathrm{C}$ has been used experimentally. An alloy of Zinc/Tin (80/30) and a eutectic mixing of diphenyl oxide and biphenyl has been studied as the phase change materials-heat transfer fluid system to produce high temperature super-heated vapor with temperature range of 340-399 $\mathrm{C}$ (Lopez et al., 2010).

\subsection{Heat Pipes for Enhancement}

As we know that the heat pipes have good effective thermal conductivity. They may incorporate through the PCMs storage systems for serving the heating energy among the PCMs and the HTFs. Figure 12 presents a PCM heating storage system by utilizing the heat pipes for heat transport improving (Steinmann and Tamme, 2008). The heat pipes could transport heat among the PCMs and the HTFs with the condensation and evaporation of heat pipe operation liquid which occurred at the heat pipes ends.

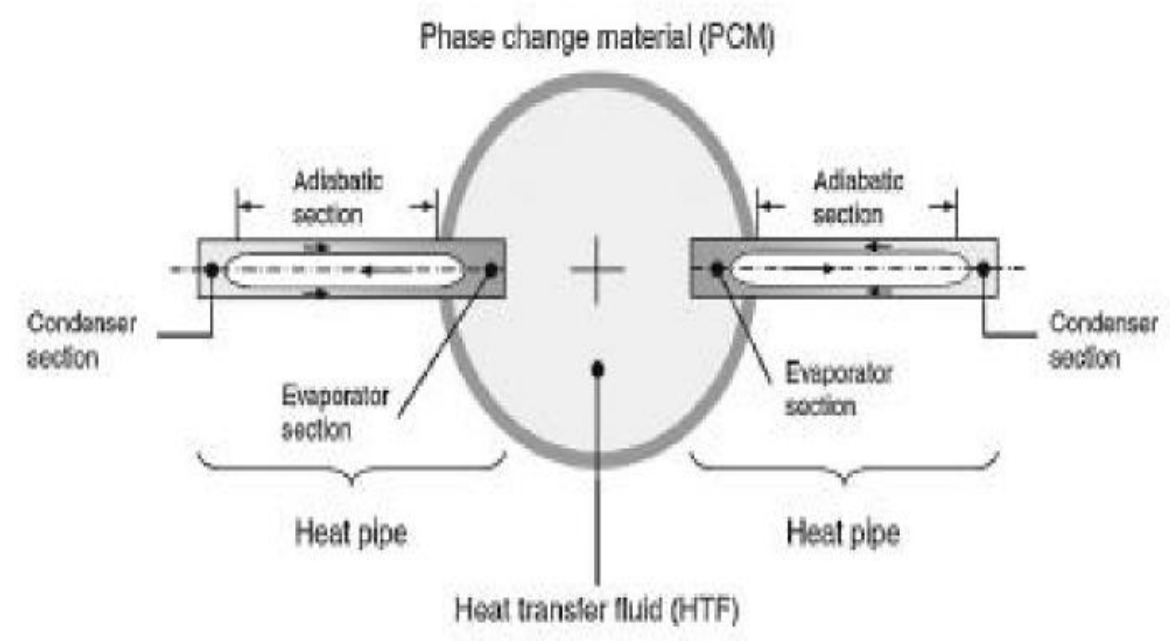

Figure 12. Phase change materials heat transfer (Steinmann and Tamme, 2008)

\subsection{Multiple PCMs for Enhancement}

Thermal storage systems adopted multiple PCMs with various melting temperatures was also attractive to enhance heat transport technology. In the phase change materials system, a few modules were containing various phase change materials and various melting temperatures were fixed in series. The multiple phase change materials have been employed for enhancing the thermal efficiency for systems of latent storage. It was significant to choose the proper phase change materials and the phase change materials relative appropriate. The multiple phase change materials in shell-tube units must be in the flow direction that the melting temperature increases in the discharging process and reduces in the charging process (Steinmann and Tamme, 2008). The rate of heat transfer in the storage unit was depending on the temperature difference between the PCM and the HTF. If a single phase change materials was utilized, this difference gradually decreases in the heat transfer fluid flow direction, and the results of the rate decreasing of the heat transport. If multiple phase change materials were consisted of the storage unit in the series, the difference of temperature may be refer to roughly constant as both the heat transfer fluid temperature and the melting point of the phase change materials reduce in the heat transfer fluid flow direction in the charging process and both of them increase in the heat transfer fluid flow direction in the discharging process. Therefore, the heat flux from the phase change materials to the heat transfer fluid was closely constant. For the case that the encapsulated phase change materials was immersed in a large storage container so that the temperature variation of the heat transfer fluid may ignore with the flow direction, in order to extract maximum achieving, the multiple phase change materials might be designed in the radial direction rather than in axial direction as flow direction (Steinmann and Tamme, 2008). Wang et al. (2001) were studied experimentally the melting process of a cylindrical thermal storage capsule which was filled by three phase 
change materials with lowest melting point phase change materials at center and other phase change materials designed for increasing melting point from center to outer. The thermal efficiency for same capsule with only phase change materials evaluated for same comparison. Results illustrated that melting time has $36-41 \%$ shorter in the three phase change materials capsule than that in the single phase change materials capsule. The evaluation of the thermal efficiency of a thermal storage system using three phase change materials and filled in a number of cylindrical capsules with air flowing across them has been performed by (Adinberg et al., 1999; Shabgard et al., 2010). A similar conclusion (Jegadheeswaran and Pohekar, 2009; Wang et al., 2001) showed that the performance of a thermal porous storage system focusing five phase change materials was from $12 \%$ to $25 \%$ higher than that of single phase change materials system. A study to design and tested a vertical shell and tube thermal storage system with 3 high temperature phase change materials-KNO3 (first phase change materials), eutectic $\mathrm{KNO} / \mathrm{KCl}$ (second phase change materials) and $\mathrm{NaNO} 3$ (third phase change materials) has introduced by Michels and Paal (1989). This system has adapted to the one using of parabolic trough solar energy plants. Results indicated around $92 \%$ of phase change materials in multiple phase change materials storage unit completely molten at 66 which solidified completely at end of discharging. For single storage unit containing NaNO3 as phase change materials, at least $100 \%$ of the phase change materials has molten completely at the charging end but $2 \%$ has solidified completely at discharging end. Farid et al. (1990) clarify the reason of multiple phase change materials unit have given higher using of possibly PCM. A multiple PCMs storage unit also has the higher exergy performance (Adebiyi et al. 1996; Michels and Pitz-Paal, 2007) and offers uniform heat transfer fluid outlet temperature (Farid et al., 1989; Adine and Qarnia, (2009).

\section{Conclusions}

The solar thermal applications are reviewed with focusing to the two main subsystems: heating energy storage subsystems and solar collectors. Many of solar collectors are discussed, consisting concentrating and non-concentrating types. For non-concentrating collectors, the PVT solar collectors conclude the best efficiency. Heat transfer augmentation has necessary to overcome the low heat transfer for these applications. For this purpose, graphite composites and metal foams were studied to be the perfect materials. Finally, the current status of existing solar power stations is reviewed, with potential developments future research being suggested. The high temperature phase change materials with melting temperatures above $45^{\circ} \mathrm{C}$ were included. The promising substances consisted salt eutectics, pure inorganic salts, metals and metallic eutectic alloys. Number of pure inorganic salts and salt eutectics focused on the chlorides basis, nitrates and carbonates which have low cost. The assessment of the thermal properties of various phase change materials is studied. The applications of the heat storage utilized as a part of solar air heating systems, solar water heating systems, solar green house, solar cooking, space heating and cooling buildings application, off peak electricity storage systems, waste heat recovery systems. This review paper also introduces the melt fraction studies of the few identified phase change materials utilized in many storage systems applications with different heat exchanger container materials. The research and development is based and productive, concentrating on both the resolution of specific phase change materials and problems and the study of the characteristics of new materials. This review paper appears the different heat transfer solution methods have been employed by different investigator. The experimental, theoretical and numerical studies have been carried out on the thermophysical properties of new materials with phase change. There are five pure inorganic salts based on nitrates and hydroxides with different range of melting temperatures, the fusion latent heats of more potential phase change materials within the range of melting temperatures in binary and ternary chloride eutectic salts. They also found the high latent heat of fusion, most of which were above $250 \mathrm{~kJ} \mathrm{~kg}-1$. Identifying a suitable phase change materials has been one aspect in the development of a high temperature phase change thermal storage system. Another aspect and also a challenge were to improve the system thermal efficiency due to the low thermal conductivity of salts. The thermal performance augmentation methods employed in phase change thermal storage systems with high temperature.

\section{References}

Abdallah, S. (2004). The effect of using sun tracking systems on the voltage-current characteristics and power generation of flat plate photovoltaics. Energy Convers Manage, 45, 1671-9. http://dx.doi.org/10.1016/j.enconman.2003.10.006

Adebiyi, G. A., Hodge, B. K., Steele, W. G., Jalalzadeh-Azar, A., \& Nsofor, E. C. (1996). Computer simulation of a high-temperature thermal energy storage system employing multiple families of phase-change storage materials. Journal of Energy Resources Technology, 118, 102-11. http://dx.doi.org/10.1115/1.2792700.

Adinberg, R., Yogev, A., \& Kaftori, D. (1999). High temperature thermal energy storage an experimental study. $J$ 
Phys IV France; 9:PR3. http://dx.doi.org/10.1051/jp4:1999314

Adinberg R., Zvegilsky D., \& Epstein M. (2010). Heat transfer efficient thermal energy storage for steam generation. Energy Conversion and Management, 51, 9-15. http://dx.doi.org/10.1016/j.enconman.2009.08.006

Adine, H. A., \& El, Q. H. (2009). Numerical analysis of the thermal behaviour of a shell-andtube heat storage unit using phase change materials. Applied Mathematical Modelling, 33, 2132-44. http://dx.doi.org/10.1016/j.apm.2008.05.016

Agarwal, R. K., \& Garg, H. P. (1994). Study of a photovoltaic thermal system thermosyphonic solar water heater combined with solar cells. Energy Convers Manage, 35, 605-20. http://dx.doi.org/ 10.1016/0196-8904(94)90044-2

Ahmad, F. et al. (2011). Analytical and Experimental Studies on thermal Efficiency of the Double pass Solar Air Collector with Finned Absorber. American Journal of Applied science, 8, 716-723. http://dx.doi.org/10.3844/ajassp.2011.716.723

Alvarez, G., Arce, J., Lira, L., \& Heras, M. R. (2004). Thermal Performance of an Air Solar Collector with an Absorber Plate Made of Recycable ALuminium Cans. Solar Energy, 77, 107-113. http://dx.doi.org/10.1016/j.solener.2004.02.007

Aste, N., Chiesa, G., \& Verri, F. (2008). Design, development and performance monitoring of a photovoltaic-thermal (PVT) air collector. Renew Energy, 33, 914-27. http://dx.doi.org/10.1016/j.renene.2007.06.022

Bakos, G. C. (2006). Design and construction of a two-axis Sun tracking system for parabolic trough collector (PTC) efficiency improvement. Renew Energy, 31, 2411-21. http://dx.doi.org/10.1016/j.renene.2005.11.008

Bashira, A. A.Y. (2005). Prediction Study on Single and Double flow Solar Air Heater. Suranaree J. sci. A Technol, 123-136.

Battleson, K. W. (1981). Solar power tower design guide: solar thermal central receiver power systems. Sandia National Labs, Report SAND81-8005.

Bauer, T., Tamme, R., Christ, M., \& Ottinger, O. (2006). PCM-graphite composites for high temperature thermal energy storage. In: Ecostock' 2006-10th international conference on thermal energy storage.

Ben, S. R., Bouabdallah, M., \& Mora, J. C. (1996). Air solar Collector with Baffles Aerodynamics, Heat Transfer and Efficiency. RERIC International Energy Journal, 18(1), 1-17.

Bergene, T., \& Lovvik, O. M. (1995). Model calculations on a flat-plate solar heat collector with integrated solar cells. Sol Energy, 55, 453-62. http://dx.doi.org/10.1016/0038-092X(95)00072-Y

Bhagoria, J. L., Saini, J. S., \& Solanki, S. C. (2002). Heat Transfer Coefficient and Fricition Factor Correlaltions for Rectangular Solar Air Heater Duct Having Transverse Wedge Shaped Rib Roughness on the Absorber Plate. Renewable Energy, 25, 341-369. http://dx.doi.org/10.1016/S0960-1481(01)00057-X

Choudhury, C. (1995). Performance and Cost Analysis of two pass Solar air Heater. Heat Recovery Systems and CHP, 15(8), 95,755-773. http://dx.doi.org/10.1016/0890-4332(95)00003-H

Coventry, J. (2002). Simulation of a concentrating PV/thermal collector using TRNSYS. In: Proceedings of the ANZSES solar energy conference.

De Winter, F. (1991). Solar collectors, energy storage, and materials. Massachusetts: The MIT press.

Farid, M. M., Kim, Y., Kansawa, A. (1990). Thermal performance of a heat storage module using PCM's with different melting temperature: experimental. Journal of Solar Energy Engineerin, 112, 125-31. http://dx.doi.org/10.1115/1.2929644

Farid, M. M, \& Kanzawa, A. (1989). Thermal performance of a heat storage module using PCM's with different melting temperatures: mathematical modeling. Journal of Solar Energy Engineering, 111, 152-7. http://dx.doi.org/10.1115/1.3268301

Foued, C., Noureddine, M., Abdelhafid, B., \& Said, B. (2013). Thermal Efficiency Analysis of a Single Flow Solar Air Heater with Different Mass Flow Rates In A Smooth Plate. Frontiers in Heat and Mass Transfer. http://dx.doi.org/10.5098/hmt.v4.1.3006

Francia, G. (1961). A new collector of solar radiant energy. In: Proceedings of the united nations conference on 
new sources of energy, p. 572.

Fujisawa, T., \& Tani, T. (2001). Optimum design for residential photovoltaic-thermal binary utilization system by minimizing auxiliary energy. Electr Eng Jpn, 137, 28-35. http://dx.doi.org/10.1002/eej.1077

Gaur, G. (2010). An Experimental investigation of a novel design of double pass solar air heater. International Journal of chem. Tech Research, 5, 1036-1040.

Gokon, N., Nakano, D., Inuta, S., Kodama, T. (2008). High-temperature carbonate/MgO com- posite materials as thermal storage media for double-walled solar reformer tubes. Solar Energy, 82, 1145-53. http://dx.doi.org/10.1016/j.solener.2008.05.011

Gonzalez, S. (2012) .Thermal Evaluation and Modeling of Double-pass solar Collector For Air Heating. Conference, opportunities, limit \& Need Towered an environmental responsible, 7-9.

Gupta, B., Waiker, J. K., Manikpuri, G. P., \& Bhalavi, B. S. (2013). Experimental Analysis of Single and Double Pass Smooth Plate Solar Air Collector with and without Porous Media. American Journal of Engineering Research, 2(12), 144-149.

Hale, D. V., Hoover, M. J., \& O’Neill, M. J. (1971). Phase change materials hand book. Alabaa: Marshal Space Flight Center.

Hegazy, A. A. (2000). Comparative study of the performances of four photovoltaic/thermal solar air collectors. Energy Convers Manage, 41, 861-81. http://dx.doi.org/10.1016/S0196-8904(99)00136-3

Hellstrom, B., Adsten, M., Nostell, P., Karlsson, B., \& Wackelgard, E. (2003). The impact of optical and thermal properties on the performance of flat plate solar collectors. Renew Energy, 28, 331-44. http://dx.doi.org/10.1016/S0960-1481(02)00040-X

Ho, C. D., Yeh, H. M., \& Wang, R. C. (2005). Heat-transfer enhancement in double-pass flat plate solar air heaters with recycle. Energy, 30, 2796-817. http://dx.doi.org/10.1016/j.energy.2005.01.006

Jegadheeswaran, S., \& Pohekar, S. D. (2009). Performance enhancement in latent heat thermal storage system: A review. Renewable and Sustainable Energy Reviews, 13, 2225-44. http://dx.doi.org/10.1016/j.rser.2009.06.024

Joshi, A. S., \& Tiwari, A. (2007). Energy and exergy efficiencies of a hybrid photovoltaic-thermal (PV/T) air collector. Renew Energy, 32, 2223-41. http://dx.doi.org/10.1016/j.renene.2006.11.013

Kacira, M., Simsek, M., Babur, Y., \& Demirkol, S. (2004). Determining optimum tilt angles and orientations of photovoltaic panels in Sanliurfa, Turkey. Renew Energy, 29, 1265-75. http://dx.doi.org/10.1016/j.renene.2003.12.014

Kalogirou, S. A. (2001). Use of TRNSYS for modelling and simulation of a hybrid PV-thermal solar system for Cyprus. Renew Energy, 23, 247-60. http://dx.doi.org/10.1016/S0960-1481(00)00176-2

Khoukhi, M., \& Maruyama, S. (2005). Theoretical approach of a flat plate solar collector with clear and low-iron glass covers taking into account the spectral absorption and emission within glass covers layer. Renew Energy, 30, 1177-1194. http://dx.doi.org/10.1016/j.renene.2004.09.014

Konttinen, P., Lund, P. D., \& Kilpi, R. J. (2003). Mechanically manufactured selective solar absorber surfaces. Sol Energy Mat Sol C, 79, 273-83. http://dx.doi.org/ 10.1016/S0927-0248(02)00411-7

Kumar, K. R., \& Reddy, K. S. (2009). Thermal analysis of solar parabolic trough with porous disc receiver. Appl Energy, 86, 1804-12. http://dx.doi.org/10.1016/j.apenergy.2008.11.007

Lambert, A. A., Cuevasa, S., \& del Río, J. A. (2006). Enhanced heat transfer using oscillatory flows in solar collectors. Sol Energy, 80, 1296-302. http://dx.doi.org/10.1016/j.solener.2005.04.029

LESOPB/EPFL, Enecolo, A. G., \& Ernst, S. A. G. (2000). New generation of Hybrid Solar PV/T collectors, report for Swiss Federal Office of Energy, 1-55.

Lopez, J., Caceres, G., Palomo, D. E., \& Jomaa, W. (2010). Confined melting in deformable porous media: a first attempt to explain the graphite/salt composites behaviour. International Journal of Heat and Mass Transfer, 53, 1195-207. http://dx.doi.org/10.1016/j.ijheatmasstransfer.2009.10.025

Medrano, M., Gil, A., Martorell, I., Potou, X., \& Cabeza, L. F. (2010). State of the art on high-temperature thermal energy storage for power generation. Part 2-Case studies. Renew Sust Energy Rev., 14, 56-72. http://dx.doi.org/10.1016/j.rser.2009.07.035 
Michels, H., \& Pitz-Paal, R. (2007). Cascaded latent heat storage for parabolic trough solar power plants. Solar Energy, 81, 829-37. http://dx.doi.org/10.1016/j.solener.2006.09.008

Moummi, N., Youcef-Ali, S., Moummi, A., \& Desmons, J. Y. (2004). Energy Analysis of Solar Air Collector with Rows of fins. Renewable Energy, 29, 2053-2064. http://dx.doi.org/10.1016/j.renene.2003.11.006

Nelson, J. (2003). The physics of solar cells. London: Imperial College Press.

Omojaro, A. P., \& Aldabbagh, L. B. Y. (2010). Experimental Performance of Single and Double Pass Solar Air Heater with Fins and Steel Wire Mesh Absorber. Applied Energy, 87, 3759-3765. http://dx.doi.org/10.1016/j.apenergy.2010.06.020

Orel, Z. C., Gunde, M. K., \& Hutchins, M. G. (2002). Spectrally selective solar absorbers in different non-black colours. In: Proceedings of WREC VII (CD-ROM), Cologne, Germany.

Ozgen, F., Esen, M., \& Esen, H. (2009). Experimental Investigation of Thermal Performance of a Double-Flow Solar Air Heater Having Aluminium Cans. Renewable Energy, 34, 2391-2398. http://dx.doi.org/10.1016/j.renene.2009.03.029

Ozturk, H. H., \& Demirel, Y. (2004). Exergy-Based Performance Analysis of Packed Bed Solar Air Heaters. International Journal of Energy Research, 28, 423-432. http://dx.doi.org/10.1002/er.974

Palmer, K. F., \& Williams, D. (1974). Optical properties of water in the near infrared. J Opt Soc Am, 64, 1107-10. http://dx.doi.org/10.1364/JOSA.64.001107

Parabolic dish collector (2012). Retrieved November 16, 2014, from http://www.geni.org/globalenergy/library/articles-renewableenergy-transmission/solar.shtml

Parsons, R., \& Ashrae, A. (1995). Handbook: heating, ventilating, and air-conditioning applications. In: Chapter 30. Atlanta: ASHRAE.

Peng, D., Zhang, X., \& Dong, H. (2010). Performance Study of a Novel Solar Collector. Applied Thermal Engineering, 30, 2594-2601. http://dx.doi.org/10.1016/j.applthermaleng.2010.07.010

Petri, R. J., Ong, E. T., \& Olszewski, M. (1984). High temperature composite thermal storage systems. In: 19th Intersociety energy conversion engineering conference.

Pincemin, S., Olives, R., Py, X., \& Christ, M. (2008). Highly conductive composites made of phase change materials and graphite for thermal storage. Solar Energy Materials and Solar Cells, 92, 603-13. http://dx.doi.org/10.1016/j.solmat.2007.11.010

Platz, R., Fischer, D., Zufferey, M. A., Anna, S. J. A., Haller, A., \& Shah, A. (1997). Hybrid collectors using thin-film technology. In: Proceedings of the $26^{\text {th }}$ photovoltaics specialists conference (IEEE). p.1293-96.

Prakash, J. (1994). Transient analysis of a photovoltaic thermal solar collector for cogeneration of electricity and hot air water. Energy Convers Manage, 35, 967-72. http://dx.doi.org/10.1016/0196-8904(94)90027-2

Prasad, S.B., J.S. Saini and K.M. Singh (2009). Investigation of Heat Transfer and Friction Characteristics of Packed Bed Solar Air Heater Using Wire Mesh as Packing Material. Solar Energy, 83, 773-783. http://dx.doi.org/10.1016/j.solener.2008.11.011

Robles-Ocampo, B., Ruíz-Vasquez, E., Canseco-Sánchezb, H., Cornejo-Mezac, R. C., TrápagaMartínezd, G., \& García-Rodrigueza, F. J. et al. (2007). Photovoltaic/thermal solar hybrid system with bifacial PV module and transparent plane collector. Sol Energy Mat Sol C, 91, 1966-71. http://dx.doi.org/10.1016/j.solmat.2007.08.005

Shabgard, H., Bergman, T. L., Sharifi, N., \& Faghri, A. (2010). High temperature latent heat thermal energy storage using heat pipes. International Journal of Heat and Mass Transfer, 53, 2979-88. http://dx.doi.org/10.1016/j.ijheatmasstransfer.2010.03.035

Slaman, M., \& Griessen, R. (2009). Solar collector overheating protection. Sol Energy, 83, 982-7. http://dx.doi.org/10.1016/j.solener.2009.01.001

Sopian, K., Alghoul, M. A., Alfegi, E. M., Sulaiman, M. Y., \& Musa, E. A. (2009). Evaluation of thermal efficiency of double pass-solar collector with porous nonporous media. Renewable Energy, 34, 640-645. http://dx.doi.org/10.1016/j.renene.2008.05.027

Steinmann, W. D., Laing, D., \& Tamme, R. (2009). Development of PCM storage for process heat and power generation. Journal of Solar Energy Engineering, 131, 041004-9. http://dx.doi.org/10.1115/1.3197834 
Steinmann, W. D., \& Tamme, R. (2008). Latent heat storage for solar steam systems. Journal of Solar Energy Engineering, 130, 011004-5. http://dx.doi.org/10.1115/1.2804624

Stirling engine attached to parabolic dish collector. Retrieved November 16, 2014, from http://www.ejsong.com/mdme/memmods/MEM23041A/thermo/heat_engines_files/Solar_Stirling.html

Tamme, R., Taut, U., Streuber, C., \& Kalfa, H. (1991). Energy storage development for solar thermal processes. Solar Energy Materials, 24, 386-96. http://dx.doi.org/10.1016/0165-1633(91)90077-X

Tavakolpour, A. R., Zomorodian, A., \& Golneshan, A. A. (2008). Simulation, construction and testing of a two-cylinder solar Stirling engine powered by a flat-plate solar collector without regenerator. Renew Energy, 33, 77-87. http://dx.doi.org/10.1016/j.renene.2007.03.004

Tina, G. M., Rosa-Clot, M., Rosa-Clot, P., \& Scandura, P. F. (2012). Optical and thermal behavior of submerged photovoltaic solar panel: SP2. Energy, 39, 17-26. http://dx.doi.org/10.1016/j.energy.2011.08.053

Tonui, J. K., \& Tripanagnostopoulos, Y. (2007). Improved PV/T solar collectors with heat extraction by forced or natural air circulation. Renew Energy, 32, 623-37. http://dx.doi.org/10.1016/j.renene.2006.03.006

Tripanagnostopolous, Y., Souliotis, M., \& Nousia, T. (2000). Solar collectors with colored absorbers. Sol Energy, 68, 343-56. http://dx.doi.org/10.1016/S0038-092X(00)00031-1

Wang, J., Ouyang, Y., \& Chen, G. (2001). Experimental study on charging processes of a cylindrical heat storage capsule employing multiple-phase-change materials. International Journal of Energy Research, 25, 439-47. http://dx.doi.org/ 10.1002/er.695

Wang, R. Z., \& Zhai, X. Q. (2012). Development of solar thermal technologies in China. Energy, 35, 4407-16. http://dx.doi.org/10.1016/j.energy.2009.04.005

Wazwaz, J., Salmi, H., \& Hallak, R. (2002). Solar thermal performance of a nickel-pigmented aluminium oxide selective absorber. Renew Energy, 27, 277-92. http://dx.doi.org/10.1016/S0960-1481(01)00192-6

Wei, X. D., Lu, Z. W., Wang, Z. F., Yu, W. X., Zhang, H. X., \& Yao, Z. (2010). A new method for the design of the heliostat field layout for solar tower power plant. Renew Energy, 35, 1970-5. http://dx.doi.org/10.1016/j.renene.2010.01.026

Zhang, P., Song, L., Lu, H., Wang, J., \& Hu, Y. (2010). The influence of expanded graphite on thermal properties for paraffin/high density polyethylene/chlorinated paraffin/antimony trioxide as a flame retardant phase change material. Energy Conversion and Management, 51, 2733-7. http://dx.doi.org/10.1016/j.enconman.2010.06.009

Zhang, Y., Lin, B., \& Chen, J. (2007). Optimum performance characteristics of an irreversible solar-driven Brayton heat engine at the maximum overall efficiency. Renew Energy, 32, 856-67. http://dx.doi.org/10.1016/j.renene.2006.02.008

Zondag, H. A., De Vries, D. W., Van Helden, W. G. J., Van Zolingen, R. J. C., \& Van Steenhoven, A. A. (2002). The thermal and electrical yield of a PV-thermal collector. Sol Energy, 72, 113-28. http://dx.doi.org/10.1016/S0038-092X(01)00094-9

\section{Copyrights}

Copyright for this article is retained by the author(s), with first publication rights granted to the journal.

This is an open-access article distributed under the terms and conditions of the Creative Commons Attribution license (http://creativecommons.org/licenses/by/3.0/). 